\title{
Free Androgen Index and Leptin Are the Most Prominent Endocrine Predictors of Ovarian Response during Clomiphene Citrate Induction of Ovulation in Normogonadotropic Oligoamenorrheic Infertility*
}

\author{
BABEK IMANI, MARINUS J. C. EIJKEMANS, FRANK H. DE JONG, \\ NADIA N. PAYNE, PHILIPPE BOUCHARD, LINDA C. GIUDICE, AND \\ BART C. J. M. FAUSER \\ Division of Reproductive Medicine, the Department of Obstetrics and Gynecology (B.I., B.C.J.M.F.), \\ Center for Clinical Decision Sciences, and the Departments of Public Health (M.J.C.E.) and Internal \\ Medicine III (F.H.J.), Erasmus University Medical Center, 3015 GD Rotterdam, The Netherlands; \\ Cobbold Laboratories (N.P.), Middlesex Hospital, WIN 8AA London, United Kingdom; Service \\ d'Endocrinologie (P.B.), Hopital Saint Antoine, 75571 Paris, France; and the Division of Reproductive \\ Endocrinology and Infertility, Department of Obstetrics and Gynecology, Stanford University Medical \\ Center (L.C.G.), Stanford, California
}

\begin{abstract}
We have previously demonstrated that obese hyperandrogenic amenorrheic women are less likely to ovulate after clomiphene citrate (CC) medication. The present study was designed to identify whether additional endocrine screening characteristics, all potentially involved in ovarian dysfunction in 182 normogonadotropic oligoamenorrheic infertile women, are associated with ovarian response, which may improve overall prediction of CC-resistant anovulation. Standardized endocrine screening took place before initiation of CC medication $(50 \mathrm{mg} /$ day; increasing doses up to $150 \mathrm{mg} /$ day if required) from cycle days 3-7. Screening included serum assays for fasting insulin and glucose, insulin-like growth factor I (IGF-I), IGF-binding protein-1 (IGFBP-1), IGFBP-3, free IGF-I, inhibin B, leptin, and vascular endothelial growth factor. Forty-two women (22\% of the total group) did not ovulate at the end of follow-up (a total number of 325 cycles were analyzed). Fasting serum insulin, insulin/glucose ratio, IGFBP-1, and leptin were all significantly different in univariate analyses $(P \leq 0.02)$, comparing $\mathrm{CC}$ responders $v s$. nonresponders. Forward stepwise multivariate analyses in combination with factors reported earlier for prediction of patients remaining anovulatory after
\end{abstract}

CC revealed a prediction model including 1) free androgen index $(\mathrm{FAI}=$ testosterone/sex hormone-binding globulin ratio), 2) cycle history (oligomenorrhea or amenorrhea), 3) leptin level, and 4) mean ovarian volume. These data suggest that decreased insulin sensitivity, hyperandrogenemia, and obesity, all associated with polycystic ovary syndrome, are prominent factors involved in ovarian dysfunction, preventing these ovaries from responding to stimulation by raised endogenous FSH levels due to CC medication. By using leptin instead of body mass index or waist to hip ratio, the previous model for prediction of patients remaining anovulatory after CC medication could be slightly improved (area under the curve from $0.82-0.85$ ). This may indicate that leptin is more directly involved in ovarian dysfunction in these patients. The capability of insulin and IGFBP-1 to predict patients who remain anovulatory after $\mathrm{CC}$ disappears when FAI enters into the model due to a significant correlation between FAI and these endocrine parameters. This suggests that markers for insulin sensitivity (e.g. IGFBP-1 and insulin) are associated with abnormal ovarian function through its correlation with androgens, whereas leptin is directly involved in ovarian dysfunction. (J Clin Endocrinol Metab 85: 676-682, 2000)
C LOMIPHENE CITRATE (CC) is considered to be the first line strategy for ovulation induction in normogonadotropic anovulatory infertility (WHO group 2) (1) since its clinical introduction almost 4 decades ago (2). This synthetic steroid, characterized by its mixed estrogenic and antiestrogenic properties, is still extensively used. Approximately $75 \%$ of treated patients will ovulate after CC

Received July 21, 1999. Revision received October 12, 1999. Accepted October 27, 1999.

Address all correspondence and requests for reprints to: Prof. B. C. J. M. Fauser, M.D., Ph.D., Division of Reproductive Medicine, Department of Obstetrics and Gynecology, Erasmus University Medical Center, Dr. Molewaterplein 40, 3015 GD Rotterdam, The Netherlands. E-mail: fauser@gyna.azr.nl.

* This work was supported by the Stichting Voortplantingsgeneeskunde Rotterdam (to B.C.J.M.F.), by an unrestricted research grant from Ferring Pharmaceuticals Ltd. Nederland BV (to B.C.J.M.F.), and in part by NIH Grant HD-31579 (to L.C.G.). medication (3-5), and once ovulation is achieved, cumulative conception rates are $75 \%$ within six consecutive CC cycles $(4$, 6-8).

Polycystic ovary syndrome (PCOS), usually referred to as chronic hyperandrogenic anovulation (9), is a common endocrine disorder and represents a significant proportion of normogonadotropic anovulatory infertility (10). Etiological factors involved in ovarian dysfunction in this heterogeneous patient group have not yet been fully elucidated. Various investigators reported on the prominent role of locally produced growth factors, such as insulin-like growth factors (IGFs) (11-13) or vascular endothelial growth factor (VEGF) (14). Moreover, recent evidence suggests that decreased insulin sensitivity plays an important role in initiating ovarian dysfunction in these patients, possibly by stimulating thecal cell androgen production $(15,16)$. A significant proportion of patients with PCOS suffer from severe obesity $(17,18)$, and 
therefore, leptin, the hormone product of the obesity gene (19), has been the focus of intense investigation (20-23). It has been demonstrated that leptin can impair insulin action in hepatocytes (20). Although leptin does not appear to play a direct role in either hyperandrogenemia or hypersecretion of LH (23), abnormalities in its signaling may be involved in hypogonadotropic hypogonadism (24) and in certain cases of PCOS (21). Finally, inhibin B, which has been shown to be produced by healthy antral follicles under the control of FSH in the early follicular phase of the normal menstrual cycle (25), may serve as a marker for the severity of ovarian dysfunction in PCOS patients $(26,27)$.

We previously demonstrated that obese, hyperandrogenic, amenorrheic women are less likely to respond to stimulation by increasing endogenous FSH levels after CC compared to normal weight, oligomenorrheic women presenting with normal androgen concentrations (5). This approach may have clinical implications in terms of health economics, but may also provide information regarding factors involved in ovarian dysfunction in these women. We now report on the predictive power of additional endocrine screening of factors potentially involved in ovarian abnormalities in this patient population, including insulin sensitivity, the IGF system, leptin, inhibin B, and VEGF.

\section{Subjects and study protocol}

Materials and Methods

Between February 1993 and January 1998, 182 women attending our infertility unit presenting with 1) oligomenorrhea (bleeding intervals between 35 days and 6 months) or amenorrhea (bleeding interval $>6$ months), 2) serum FSH levels within normal limits (1-10 IU/L) $(1,28)$ and normal serum PRL and TSH levels, 3) spontaneous menses or positive bleeding response to progestagen withdrawal, 4) body mass index (BMI; weight divided by height squared) more than $18 \mathrm{~kg} / \mathrm{m}^{2}$, and $5)$ age between 19-40 ys were included in the present study. Study approval was obtained from the human subjects committee of the Dijkzigt Hospital/Erasmus University, and informed consent was obtained from all subjects.

Standardized initial clinical, sonographic, and endocrine screening took place before initiation of induction of ovulation with CC medication, as described previously (5). Clinical screening included age, infertility and cycle history, BMI, waist to hip ratio (WHR), previous medication, and/or surgery. Transvaginal sonographic screening included assessment of the ovarian stroma echogenicity (arbitrarily classified from one to three per ovary), ovarian volume (milliliters), and total number of follicles (both ovaries), as described previously $(10,29)$. Endocrine screening included serum assays for FSH, PRL, TSH, LH, estradiol, androstenedione, testosterone, and sex hormone-binding globulin (SHBG), as described previously (5). In addition, serum was assayed for fasting insulin and glucose, free and total IGF-I, IGF-binding protein-1 (IGFBP-1), IGFBP-3, inhibin B, leptin, and VEGF concentrations. Fasting venous blood samples were taken on a random day between 0800-1000 h before initiation of therapy. Blood samples were centrifuged within $2 \mathrm{~h}$ after withdrawal and stored at $-20 \mathrm{C}$ until assayed.

\section{Hormone assays}

Serum insulin levels were measured by immunoradiometric assay (IRMA; Biosource Technologies, Inc., Fleurus, Belgium), glucose levels by the hexokinase method (Gluco-quant, Roche Molecular Biochemicals, Mannheim, Germany) (30), and free IGF-I levels by a two-site IRMA (Active, Diagnostic Systems Laboratories, Inc., Webster, TX) direct assay. Serum was incubated in tubes and decanted, and the tubes were washed according to the manufacturer's instructions. Free IGF-I, bound to the tube, was detected by radiolabeled antibody as described previously (31). Serum IGF-I levels were mea- sured using a two-site IRMA (Active, Diagnostic Systems Laboratories, Inc.), which includes an extraction step to separate the IGF-I from its binding protein in serum. IGFBP-1 and IGFBP-3 levels were assayed using a two-site IRMA (Active, Diagnostic Systems Laboratories, Inc.) assay as described previously (31). The IGFBP-3 samples were diluted 1:100 before assay. Dimeric inhibin B levels were measured using an immunoenzymometric assay (Serotec, Oxford, UK) (32), leptin levels using a RIA (by means of reagents supplied by Linco Research, Inc., St. Charles, MO) (33), and VEGF levels by enzyme immunoassay (Cytokit Red EIA kits, Peninsula Laboratories, Inc., College Park, MD) (34). Midluteal serum progesterone (P) levels were measured by RIA, as described previously (8). Intra- and interassay coefficients of variation were less than $6.1 \%$ and $9.9 \%$ for insulin, less than $1.0 \%$ and $1.9 \%$ for glucose, less than $10.3 \%$ and $10.7 \%$ for free IGF-I, less than $3.4 \%$ and $8.2 \%$ for IGF-I, less than $5.2 \%$ and $6.0 \%$ for IGFBP-1, less than $3.9 \%$ and $1.9 \%$ for IGFBP-3, less than $8 \%$ and $14 \%$ for inhibin B, less than $3.6 \%$ and $4.6 \%$ for leptin, and less than $7.8 \%$ and $12.2 \%$ for VEGF, respectively.

\section{CC ovulation induction protocol}

CC was administered at a daily dose of $50 \mathrm{mg}$ (which was increased to 100 and $150 \mathrm{mg}$ in subsequent cycles in the case of absent ovarian response) from cycle days 3-7 after initiation of a spontaneous or progestin-induced withdrawal bleeding, as described previously (5). Ovulation after $C C$ treatment was assessed by midluteal serum $P$ levels above $25 \mathrm{nmol} / \mathrm{L}$ combined with transvaginal sonographic monitoring of follicle growth until visualization of a preovulatory follicle (mean diameter, $>18 \mathrm{~mm}$ ) and subsequent disappearance or biphasic basal body temperature charts, as indicated previously (5). If ovulation occurred, the CC dose remained unaltered during subsequent cycles. The duration of follow-up for all patients included in the study was at least three treatment cycles. First ovulation after CC was used as the end point. Responders were defined as patients who ovulated after CC, independent of the dose administered. The number of treatment cycles and the CC dose in which first ovulation occurred were recorded. Clomiphene-resistant anovulation (CRA) was defined as patients who did not ovulate despite receiving maximum treatment doses of $150 \mathrm{mg} /$ day.

\section{Data analysis}

$P=0.05$ was chosen as threshold level for statistical significance in univariate analyses. For comparison of initial screening parameters of CC responders and nonresponders, we used the Mann-Whitney U test and Wilcoxon rank sum $W$ test. The univariate relation with response to $\mathrm{CC}$ was assessed using logistic regression analysis. The following initial serum parameters were used in the multivariate analyses (forward stepwise selection of variables, $P_{\text {entry }}<0.10$ ): fasting serum insulin and glucose, IGF-I, IGFBP-1, IGFBP-3, free IGF-I, inhibin B, leptin, and VEGF in combination with parameters of the previous model for prediction of patients remaining anovulatory after CC treatment, including FAI, cycle history (oligomenorrhea vs. amenorrhea), BMI, and mean ovarian volume (5). The area under the receiver operating characteristics curve (AUC) was used to assess the discriminative ability of the tests, as described previously (5). Data were analyzed using the commercially available software package SPSS, Inc. (Chicago, IL).

\section{Results}

From the total number of 182 patients fulfilling the in/ exclusion criteria and treated with CC medication, $131(72 \%)$ suffered from primary infertility, 43 (24\%) from amenorrhea, and the remaining 139 (76\%) had oligomenorrhea. Eightytwo $(45 \%)$ women were obese (BMI, $\geq 26), 113(62 \%)$ patients presented with an elevated FAI ( $\geq 4.0)$, and $67(37 \%)$ patients presented with hyperandrogenemia (testosterone, $\geq 3.2$ $\mathrm{nmol} / \mathrm{L}$; and / or androstenedione, $\geq 16.3 \mathrm{nmol} / \mathrm{L})(10,35)$. In 134 patients $(74 \%)$ polycystic ovaries (mean ovarian volume, $\geq 10.8 \mathrm{~mL}$; and/or mean follicle number per ovary, $\geq 10)(10$, $29)$ were diagnosed. Finally, 93 patients $(51 \%)$ presented with elevated serum LH levels ( $\geq 7.0 \mathrm{IU} / \mathrm{L})(10,35)$. From the total 
TABLE 1. Endocrine findings (mean \pm SD) upon initial screening of 182 normogonadotropic oligoamenorrheic infertile women ${ }^{a}$ and separately for patients who did (CC responders) or did not (CRA) ovulate after CC induction of ovulation

\begin{tabular}{|c|c|c|c|c|}
\hline & $\begin{array}{l}\text { Overall group } \\
\quad(\mathrm{n}=182)\end{array}$ & $\begin{array}{c}\mathrm{CC} \text { responder } \\
(\mathrm{n}=142 ; 78 \%)\end{array}$ & $\begin{array}{c}\text { CRA } \\
(\mathrm{n}=40 ; 22 \%)\end{array}$ & $P$ value \\
\hline Glucose $(\mathrm{mmol} / \mathrm{L})$ & $4.3 \pm 1.6$ & $4.2 \pm 1.0$ & $4.8 \pm 2.9$ & $-^{c}$ \\
\hline Insulin/glucose ratio & $3.6 \pm 2.5$ & $3.4 \pm 2.3$ & $4.4 \pm 3.0$ & 0.05 \\
\hline IGF-I $(\mathrm{ng} / \mathrm{mL})$ & $237 \pm 97$ & $242 \pm 99$ & $218 \pm 83$ & - \\
\hline Free IGF-I (ng/mL) & $2.8 \pm 1.7$ & $2.8 \pm 1.6$ & $3.0 \pm 2.0$ & - \\
\hline IGFBP-1 (ng/mL) & $24.2 \pm 18.1$ & $26.4 \pm 18.5$ & $16.7 \pm 14.5$ & 0.001 \\
\hline
\end{tabular}

${ }^{a}$ Remaining characteristics: age, $28 \pm 4.5 \mathrm{yr} ; \mathrm{BMI}, 26.5 \pm 6 \mathrm{~kg} / \mathrm{m}^{2}$; T, $2.4 \pm 0.9 \mathrm{nmol} / \mathrm{L} ; \mathrm{FAI}, 6.2 \pm 4.2 ; \mathrm{LH}, 7.9 \pm 4.4 \mathrm{IU} / \mathrm{L} ; \mathrm{FSH}, 4.5 \pm 4.6$

$\mathrm{IU} / \mathrm{L} ; \mathrm{E}_{2}, 258 \pm 174 \mathrm{pmol} / \mathrm{L}$; and mean ovarian volume, $9.8 \pm 4.2 \mathrm{~mL}$.

${ }^{b}$ Comparison of CC responders vs. CRA (by Mann-Whitney U test)

${ }^{c}$ Not significant.

group of patients, $40(22 \%)$ women remained anovulatory despite the maximum CC dose. A total number of $325 \mathrm{CC}$ cycles were analyzed (205 ovulatory and 120 anovulatory cycles).

Endocrine screening characteristics of the overall study group and separately for patients who did or did not ovulate after CC medication are presented in Table 1. Fasting insulin level, insulin/glucose ratio, and serum leptin levels were significantly higher and IGFBP-1 levels significantly lower in CRA patients. $P$ values after univariate analysis with logistic regression analyses, odds ratio, 95\% confidence interval, and the receiver operating characteristics AUC of additional initial endocrine screening parameters are depicted in Table 2. Again, serum insulin, insulin/glucose ratio, IGFBP-1, and leptin levels were significantly different between patients who did vs. those who did not ovulate after CC treatment. Results of multivariate analyses for prediction of patients remaining anovulatory after CC induction of ovulation are depicted in Table 3. Using a forward stepwise selection procedure, various significant predictors during univariate analysis (such as insulin, IGFBP-1, and BMI) disappear, and four variables were eventually selected: 1) FAI, 2) cycle history (oligomenorrhea vs. amenorrhea), 3) leptin, and 4) mean ovarian volume. The association of FAI, leptin, and insulin with other endocrine and clinical features was analyzed in more detail. Correlations between FAI and BMI, leptin, insulin, and IGFBP-1 are depicted in Fig. 1. Correlations between initial serum leptin levels and BMI, WHR, and insulin are shown in Fig. 2. Correlations between initial serum insulin levels and BMI, SHBG, and IGFBP-1 are shown in Fig. 3. For all figures, individual correlations are shown separately for CC responders and nonresponders. With the exception of leptin, correlations between all other factors depicted in the figures were significantly stronger in CC nonresponders than in responders (data not shown).

\section{Discussion}

The present prospective follow-up study was designed to evaluate whether initial screening of insulin sensitivity, the IGF system, leptin, inhibin B, or VEGF could predict the ovarian response to $\mathrm{CC}$ medication in normogonadotropic oligomenorrheic infertile women. We recently reported (5)
TABLE 2. Univariate logistic regression analyses, odds ratio, $95 \%$ confidence interval, and area under the ROC curve of endocrine screening parameters in 182 normogonadotropic oligoamenorrheic infertile women for the prediction of patients remaining anovulatory after CC induction of ovulation

\begin{tabular}{lclc}
\hline \multicolumn{1}{c}{ Univariate analyses } & Odds ratio $\left(95 \% \mathrm{CI}^{a}\right)$ & $P^{b}$ value & $\mathrm{AUC}^{c}$ \\
\hline Insulin $(\mathrm{mU} / \mathrm{L})$ & $1.05(1.01-1.08)$ & $\mathbf{0 . 0 0 5}$ & 0.64 \\
Glucose (mmol/L) & $1.21(0.97-1.50)$ & 0.07 & 0.51 \\
Insulin/glucose ratio & $1.16(1.01-1.32)$ & $\mathbf{0 . 0 3}$ & 0.61 \\
Inhibin B (ng/L) & $0.99(0.99-1.00)$ & 0.5 & 0.53 \\
IGF-I (ng/mL) & $0.99(0.99-1.00)$ & 0.2 & 0.56 \\
Free IGF-I (ng/mL) & $1.06(0.86-1.30)$ & 0.3 & 0.51 \\
IGFBP-1 (ng/mL) & $0.96(0.93-0.98)$ & $\mathbf{0 . 0 1}$ & 0.67 \\
IGFBP-3 (ng/mL) & $0.99(0.99-1.00)$ & 0.6 & 0.54 \\
Leptin (ng/mL) & $1.03(1.01-1.06)$ & $\mathbf{0 . 0 0 0 3}$ & 0.70 \\
VEGF $(\mathrm{ng} / \mathrm{mL})$ & $0.92(0.79-1.07)$ & 0.4 & 0.58 \\
\hline
\end{tabular}

${ }^{a}$ Confidence interval.

${ }^{b}$ Univariate logistic regression analyses with likelihood ratio test (Bold $=P<0.05)$

${ }^{c}$ Area under the ROC curve. (Bold $=P<0.05$ ).

that obese, hyperandrogenic, amenorrheic women, a complex of signs and symptoms frequently referred to as PCOS (9), are more likely to remain anovulatory after CC medication. As a first step we focused on screening of the most pertinent clinical, endocrine, and sonographic characteristics of these patients (5). Further endocrine parameters potentially related to ovarian dysfunction in these women are the focus of the present study. Decreased insulin sensitivity/ hyperinsulinemia or augmented free IGF-I may be involved in the pathophysiology of this heterogeneous syndrome by directly stimulating thecal cell androgen production $(13,15$, 16). Serum leptin levels were also assessed in these patients, as it has been suggested recently that this is a reliable endocrine marker for obesity. Abnormalities in its signaling pathway may be involved in hypogonadotropic hypogonadism (24) and eventually in certain cases of PCOS $(21,22)$. In addition, leptin may directly modulate insulin activity in obese individuals (20). Inhibin B is produced by healthy early antral follicles under the control of FSH in the early follicular phase of the menstrual cycle (25) and may therefore be used as a marker for the severity of ovarian abnormalities (i.e. the sensitivity to FSH and assessment of the number of healthy, rather than atretic, follicles in polycystic ovaries) and the 
TABLE 3. Forward stepwise multivariate analyses of parameters of the prediction model plus additional endocrine screening for prediction of normogonadotropic oligoamenorrheic patients remaining anovulatory during clomiphene citrate induction of ovulation

\begin{tabular}{|c|c|c|c|c|c|}
\hline \multirow{2}{*}{$\begin{array}{c}\text { Analyses: } \\
\text { Steps: }\end{array}$} & \multirow{2}{*}{$\begin{array}{c}\text { Univariate }^{a} \\
0\end{array}$} & \multicolumn{4}{|c|}{ Multivariate } \\
\hline & & 1 & 2 & 3 & $4^{b}$ \\
\hline \multicolumn{6}{|l|}{ Screening parameters } \\
\hline $\mathrm{FAI}^{d}$ & $<0.0001$ & In model & In model & In model & In model \\
\hline BMI $\left(\mathrm{kg} / \mathrm{m}^{2}\right)$ & 0.0003 & 0.03 & 0.04 & 0.46 & 0.46 \\
\hline Mean ovarian vol $(\mathrm{mL})$ & 0.007 & 0.12 & 0.13 & 0.06 & In model \\
\hline Cycle history $^{e}$ & 0.0003 & 0.0001 & In model & In model & In model \\
\hline \multicolumn{6}{|c|}{ b) Additional endocrine parameters ${ }^{f}$} \\
\hline Insulin (mU/L) & 0.005 & 0.32 & 0.45 & 0.93 & 0.98 \\
\hline Insulin/glucose ratio & 0.03 & 0.66 & 0.79 & 0.64 & 0.56 \\
\hline IGFBP-1 (ng/mL) & 0.01 & 0.82 & 0.71 & 0.74 & 0.64 \\
\hline Leptin $(\mathrm{ng} / \mathrm{mL})$ & 0.0003 & 0.01 & 0.009 & In model & In model \\
\hline
\end{tabular}

${ }^{a}$ Step 0, Comparison of CC responders vs. CRA (univariate logistic regression analyses).

${ }^{b}$ Final model, Area under the ROC curve, 0.85; multivariate odds ratio (95\% CI) of FAI, 1.19 (1.07-1.32); of cycle history, 0.16 (0.05-0.42); of mean ovarian volume, 1.11 (0.99-1.24); and of leptin, $1.04(1.01-1.06)$. This means that, for instance, a 1-U increase in a given patient's serum leptin level gives her a $4 \%$ higher probability to be a CRA.

${ }^{c}$ As published previously (5).

${ }^{d} \mathrm{FAI}=\mathrm{T} \times 100 / \mathrm{SHBG}$.

${ }^{e}$ Amenorrhea vs. oligomenorrhea.

${ }^{f}$ Only parameters that are significantly different (see Table 2 ) are included.

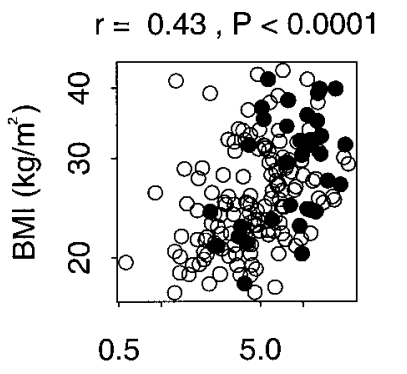

FAI

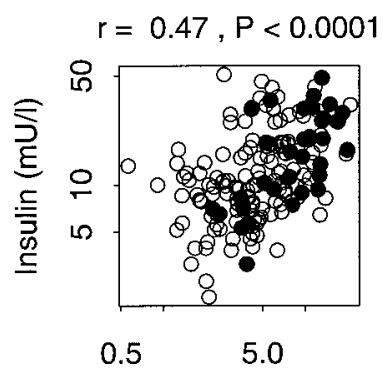

FAl
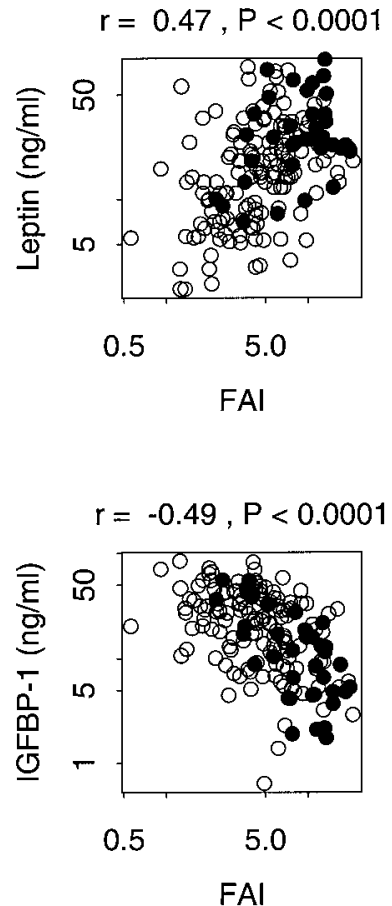

Fig. 1. Correlations between FAI (testosterone $\times 100 / \mathrm{SHBG}$ ) and BMI, serum leptin, insulin, and IGFBP-1 in 182 normogonadotropic oligomenorrheic infertile patients using a scatter plot. Open circles represent patients who ovulated after CC treatment, and closed circles represent $\mathrm{CC}$ nonresponders.

likelihood of ovaries to respond to ovulation induction (27). Finally, VEGF levels were assessed in these patients, as recent reports suggest that this protein may serve as a marker for changes in ovarian stroma of PCOS patients $(14,34)$.

The present study demonstrates that serum insulin, insulin/glucose ratio, and leptin levels are significantly higher and, in contrast, IGFBP-1 levels are lower in patients who remain anovulatory after $\mathrm{CC}$. When a multivariate analysis for the prediction of CRA is applied, the capacity of serum insulin, insulin/glucose ratio, and IGFBP-1 levels to predict CRA is eliminated when FAI enters into the model due to a strong correlation between these parameters and FAI. In contrast, leptin levels enter into the model in the third step. These results can be interpreted as follows. Insulin is significantly higher in CRA patients. An association between decreased insulin sensitivity and hyperandrogenism is well known $(36,37)$. Signal transduction via the insulin receptor has been demonstrated to be frequently abnormal in PCOS (38). Moreover, IGF-I as well as insulin have been shown to augment LH-induced androgen biosynthesis by cultured thecal cells (38). As insulin binds to the structurally similar type 1 IGF receptor, it has been postulated that high levels of circulating insulin stimulate thecal cell androgen production through the type 1 IGF receptors $(36,37)$. However, this seems to be the case only in extreme hyperinsulinism, such as in patients suffering from leprechaunism. Moreover, insulin and BMI are the major determining factors of circulating IGFBP-1 levels in both normoovulatory obese and PCOS women. Insulin reduces circulating SHBG (39-41) and IGFBP-1 levels by inhibiting the production of these proteins in the liver $(39,41)$. Apparently, the liver is excluded from reduced sensitivity for insulin stimulation. Accordingly, it has been proposed that IGFBP-1 levels may be used as a simple marker for insulin resistance (48). Several researchers indicated lower circulating levels of IGFBP-1 $(39,50,51)$, but not IGFBP-3 (51), in PCOS patients compared to normal cycling women $(33-35,48)$. Moreover, insulin may also inhibit IGFBP-1 production in ovarian granulosa cells, by acting through its own receptor (37). Circulating serum SHBG concentrations are significantly reduced in obese normoovulatory women (39) and in oligoamenorrheic CC-resistant infertile patients (5). Moreover, an increase in circulating serum SHBG concentration has been reported in ovulatory patients after CC medication (42) as well as in women with PCOS using insulin-sensitizing agents $(43,44)$. An insufficient or absent rise in circulating serum SHBG concentrations (with 


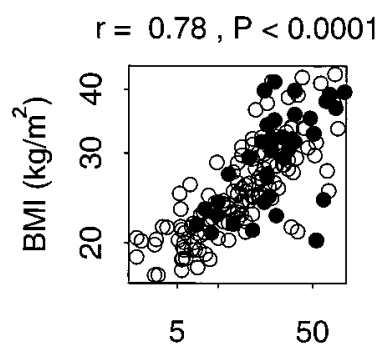

Leptin $(\mathrm{ng} / \mathrm{ml})$

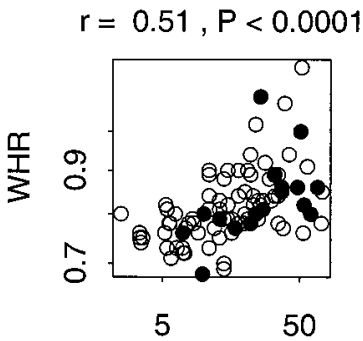

Leptin (ng/ml)

$r=0.55, P<0.0001$

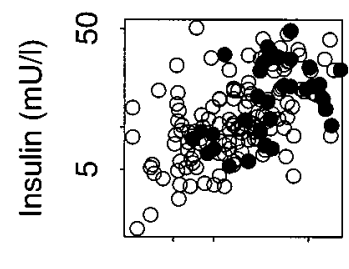

5

50

Leptin $(\mathrm{ng} / \mathrm{ml})$

FIG. 2. Correlations between serum leptin and BMI, WHR, and serum insulin in 182 normogonadotropic oligomenorrheic infertile patients using a scatter plot. Open circles represent patients who ovulated after CC treatment, and closed circles represent CC nonresponders.

resulting high free androgen levels) after CC medication could be held responsible for CC unresponsiveness.

In the present study total and free IGF-I and IGFBP-3 levels are comparable between $C C$ responders and nonresponders. No differences in IGFBP-3 levels were previously noted in follicular fluid from PCOS ovaries compared with androgendominant and estrogen-dominant follicles from normoovulatory women $(45,46)$. In contrast, IGFBP-1 levels are significantly lower in patients remaining anovulatory after CC medication. As a consequence of decreased hepatic production of serum IGFBP-1 levels, a greater proportion of IGF-I is biologically active (47). Taking into account that serum IGFBP-1 levels increase (48) and IGF-I levels decrease (42) in oligoamenorrheic women after CC medication, it may be suggested that an insufficient rise in serum IGFBP-1 levels after CC medication is involved in the follicle growth arrest in these patients. No difference could be observed in pretreatment free IGF-I levels comparing responders vs. CRA patients. Overall, FAI is the most significant factor to predict
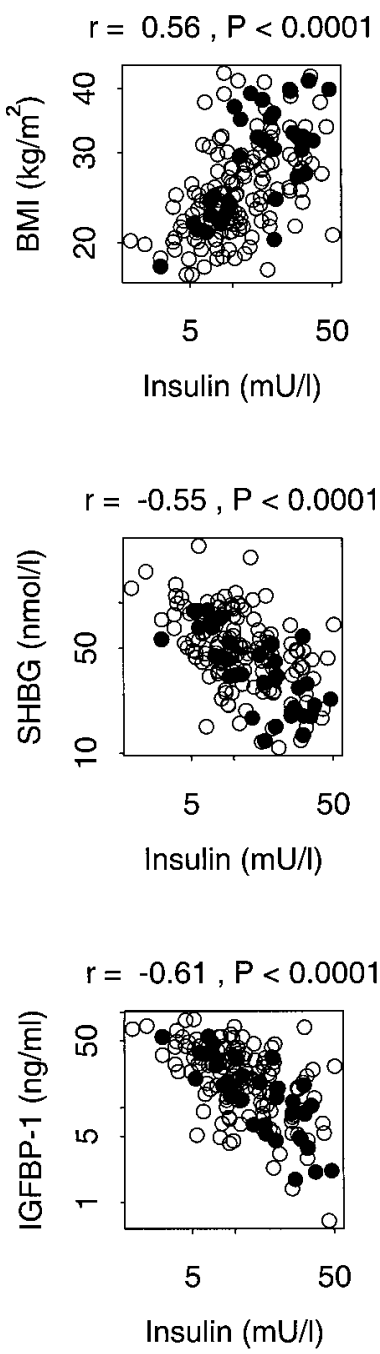

FIG. 3. Correlations between serum insulin and BMI, SHBG, and serum IGFBP-1 in 182 normogonadotropic oligomenorrheic infertile patients using a scatter plot. Open circles represent patients who ovulated after $\mathrm{CC}$ treatment, and closed circles represent $\mathrm{CC}$ nonresponders.

ovarian response. It appears that the prediction of insulin and IGFBP-1 completely depends on its association with FAI, in line with recent compelling molecular evidence for intrinsic abnormalities in the androgen synthesis pathway in PCOS thecal cells (49). It is likely that decreased IGFBP-1 is an excellent marker of hyperinsulinemia and that it does not affect the endocrine IGF system's effect on follicle growth.

The present study demonstrates a significant correlation between leptin levels and BMI and WHR, which is in agreement with previous reports (21-23). Serum leptin levels were significantly higher in CC nonresponders and enter into the model (instead of BMI) in multivariate analyses to predict CRA. The AUC of the previously developed prediction model (including FAI, BMI, cycle history, and mean ovarian volume) of 0.82 could be slightly improved to 0.85 by the inclusion of leptin rather than BMI. Due to the limited improvement of the AUC and the fact that information such as weight and height of the patient is easy to collect, one may prefer to use BMI to predict the probability of CRA in clinical 
practice. Clearly, the end point for clinical practice should be pregnancy rather than ovulation. It has been demonstrated that leptin can directly impair insulin action in hepatocytes (20). In addition, leptin directly inhibits IGF-I augmentation of FSH-stimulated estradiol production (50) as well as LHstimulated androgen synthesis in vitro (50). In vivo observations, however, would argue against a negative correlation between obesity/elevated leptin levels and androgens. High leptin levels could interfere with the ability of the dominant follicle to produce estradiol, both by inhibiting the production of androgen substrate and by decreasing the aromatizing capacity of granulosa cells (51). Moreover, changes in estradiol and $\mathrm{P}$ during the human menstrual cycle may participate in the control of leptin production (52). Caloric restriction, exercise, and weight-reducing diets may reduce leptin levels (53); result in normalization of insulin sensitivity, gonadotropins, and androgen metabolism (54); and lead to spontaneous ovulatory cycles in up to $50 \%$ of women (55).

Initial serum inhibin B as well as serum VEGF levels were similar comparing CC responders and nonresponders. These endocrine parameters had no predictive value for ovarian response to CC medication. The results of this study suggest that circulating inhibin B does not correspond to the number of healthy follicles present in polycystic ovaries, characterized by follicle maturation arrest and atresia of a proportion of follicles. This is in contrast with the conclusion of a recent report focusing on a relatively small group of patients (27). Recent observations suggest that increased intraovarian concentrations of VEGF may be related to increased stroma echogenicity and vascularity and increased secretion and pulsatility of LH (34). We have not been able to confirm that VEGF levels may represent the magnitude of ovarian dysfunction in these women.

The impact of markers for insulin sensitivity, the IGF system, leptin, inhibin B, and VEGF on the prediction of conception after ovulatory CC cycles has also been analyzed. None of these parameters predicts the probability of conceiving in women who ovulated after CC treatment (data not shown). This stresses again the concept previously put forward (8) that follicle growth and oocyte quality are differentially regulated.

In conclusion, the present longitudinal follow-up study suggests that FAI, as a marker for the severity of hyperandrogenemia, is the most significant endocrine marker of ovarian dysfunction and for the prediction of ovarian response after CC medication. Initial serum leptin insulin, and IGFBP-1 levels are factors in univariate analyses predicting patients who will remain anovulatory after CC. The capability of serum insulin and IGFBP-1 to predict CRA disappears when FAI enters into the model due to a significant correlation between FAI and these endocrine parameters. Finally, leptin is a better marker to predict ovarian response to CC medication compared to BMI. For the assessment of markers useful for clinical screening in patients, the present observations predicting ovarian response should be combined with factors predicting pregnancies in ovulatory CC women. Moreover, the question arises of whether factors involved in ovarian response or conception after CC medication may also predict individual responses to exogenous gonadotropins in patients who fail to ovulate or conceive after CC.

\section{Acknowledgments}

We gratefully acknowledge the technical expertise of Mrs. Gerry Faessen (Stanford University Medical Center) in performing the free and total IGF-I, IGFBP-1, and IGFBP-3 assays; Mrs. Najiba Lahlou (Hopital Saint Antoine) in performing leptin assays; Mrs. Joke v. d. Zwaag (Rotterdam) in performing glucose assays; Mr. Piet Uiterlinden (Rotterdam) in performing insulin assays; and Mr. Ronald van der Wal (Rotterdam) in performing inhibin B assays.

\section{References}

1. WHO. 1993 WHO manual for the standardized investigation and diagnosis of the infertile couple. Cambridge: Cambridge University Press.

2. Greenblatt RB, Barfield WE, Jungck EC, Ray AW. 1961 Induction of ovulation with MRL/41. JAMA. 178:127-130.

3. MacGregor AH, Johnson JE, Bunde CA. 1968 Further clinical experience with clomiphene citrate. Fertil Steril. 19:616-622.

4. Gorlitsky GA, Kase NG, Speroff L. 1978 Ovulation and pregnancy rates with clomiphene citrate. Obstet Gynecol. 51:265-269.

5. Imani B, Eijkemans MJ, te Velde ER, Habbema JD, Fauser BC. 1998 Predictors of patients remaining anovulatory during clomiphene citrate induction of ovulation in normogonadotropic oligomenorrheic infertility. J Clin Endocrinol Metab. 83:2361-2365.

6. Shepard MK, Balmaceda JP, Leija CG. 1979 Relationship of weight to successful induction of ovulation with clomiphene citrate. Fertil Steril. 32:641-645.

7. Hammond MG, Halme JK, Talbert LM. 1983 Factors affecting the pregnancy rate in clomiphene citrate induction of ovulation. Obstet Gynecol. 62:196-202.

8. Imani B, Eijkemans MJ, te Velde ER, Habbema JD, Fauser BC. 1999 Predictors of chances to conceive in ovulatory patients during clomiphene citrate induction of ovulation in normogonadotropic oligomenorrheic infertility. J Clin Endocrinol Metab. 84:1617-1622.

9. Dunaif A, Givens JR, Haseltine F, Merriam GR (eds). 1992 The polycystic ovary syndrome. Cambridge: Blackwell.

10. van Santbrink EJ, Hop WC, Fauser BC. 1997 Classification of normogonadotropic infertility: polycystic ovaries diagnosed by ultrasound vs. endocrine characteristics of polycystic ovary syndrome. Fertil Steril. 67:452-458.

11. Giudice LC, Morales AJ, Yen SS. 1996 Growth factors and polycystic ovarian syndrome. Semin Reprod Endocrinol. 14:203-208.

12. Cataldo NA. 1997 Insulin-like growth factor binding proteins: do they play a role in polycystic ovary syndrome? Semin Reprod Endocrinol. 15:123-136.

13. van Dessel HJ, Lee PD, Faessen G, Fauser BC, Giudice LC. 1999 Elevated serum levels of free insulin-like growth factor-1 (IGF-1) in polycystic ovary syndrome. J Clin Endocrinol Metab. 84:3030-3035.

14. Agrawal R, Conway G, Sladkevicius P, et al. 1998 Serum vascular endothelial growth factor and Doppler blood flow velocities in in vitro fertilization: relevance to ovarian hyperstimulation syndrome and polycystic ovaries. Fertil Steril. 70:651-658

15. Dunaif A. 1997 Insulin resistance and the polycystic ovary syndrome: mechanism and implications for pathogenesis. Endocr Rev. 18:774-800.

16. Nestler JE, Jakubowicz DJ, de Vargas AF, Brik C, Quintero N, Medina F. 1998 Insulin stimulates testosterone biosynthesis by human thecal cells from women with polycystic ovary syndrome by activating its own receptor and using inositolglycan mediators as the signal transduction system. I Clin Endocrinol Metab. 83:2001-2005.

17. Dunaif A, Mandeli J, Fluhr H, Dobrjansky A. 1988 The impact of obesity and chronic hyperinsulinemia on gonadotropin release and gonadal steroid secretion in the polycystic ovary syndrome. J Clin Endocrinol Metab. 66:131-139.

18. Pasquali R, Casimirri F. 1993 The impact of obesity on hyperandrogenism and polycystic ovary syndrome in premenopausal women. Clin Endocrinol (Oxf) 39:1-16.

19. Zhang Y, Proenca R, Maffei M, Barone M, Leopold L, Friedman JM. 1994 Positional cloning of the mouse obese gene and its human homologue. Nature. 372:425-432.

20. Cohen B, Novick D, Rubinstein M. 1996 Modulation of insulin activities by leptin. Science. 274:1185-1188.

21. Brzechffa PR, Jakimiuk AJ, Agarwal SK, Weitsman SR, Buyalos RP, Magoffin DA. 1996 Serum immunoreactive leptin concentrations in women with polycystic ovary syndrome. J Clin Endocrinol Metab. 81:4166-4169.

22. Rouru J, Anttila L, Koskinen P, et al. 1997 Serum leptin concentrations in women with polycystic ovary syndrome. J Clin Endocrinol Metab. 82:1697-1700.

23. Laughlin GA, Morales AJ, Yen SS. 1997 Serum leptin levels in women with polycystic ovary syndrome: the role of insulin resistance/hyperinsulinemia. J Clin Endocrinol Metab. 82:1692-1696.

24. Clement K, Vaisse C, Lahlou N, et al. 1998 A mutation in the human leptin receptor gene causes obesity and pituitary dysfunction. Nature. 392:398-401. 
25. Groome NP, Illingworth PJ, OqBrien M, et al. 1996 Measurement of dimeric inhibin B throughout the human menstrual cycle. J Clin Endocrinol Metab. 81:1401-1405.

26. Pache TD, Hop WC, de Jong FH, et al. $199217 \beta$-Oestradiol, androstenedione and inhibin levels in fluid from individual follicles of normal and polycystic ovaries, and in ovaries from androgen treated female to male transsexuals. Clin.Endocrinol (Oxf). 36:565-571.

27. Anderson RA, Groome NP, Baird DT. 1998 Inhibin A and inhibin B in women with polycystic ovarian syndrome during treatment with FSH to induce monoovulation. Clin Endocrinol (Oxf). 48:577-584.

28. van Santbrink EJ, Hop WC, van Dessel TJ, de Jong FH, Fauser BC. 1995 Decremental follicle-stimulating hormone and dominant follicle development during the normal menstrual cycle. Fertil Steril. 64:37-43.

29. Pache TD, Wladimiroff JW, Hop WC, Fauser BC. 1992 How to discriminate between normal and polycystic ovaries: transvaginal US study. Radiology. 183:421-423.

30. Neeley WE. 1972 Simple automated determination of serum or plasma glucose by a hexokinase-glucose- 6 -phosphate dehydrogenase method. Clin Chem. 18:509-515.

31. van Dessel HJ, Chandrasekher Y, Yap OW, et al. 1996 Serum and follicular fluid levels of insulin-like growth factor I (IGF-I), IGF-II, and IGF-binding protein-1 and -3 during the normal menstrual cycle. J Clin Endocrinol Metab. $81: 1224-1231$.

32. Schipper I, de Jong FH, Fauser BC. 1998 Lack of correlation between maximum early follicular phase serum follicle stimulating hormone concentrations and menstrual cycle characteristics in women under the age of 35 years. Hum Reprod. 13:1442-1448.

33. Lahlou N, Landais P, De Boissieu D, Bougneres PF. 1997 Circulating leptin in normal children and during the dynamic phase of juvenile obesity: relation to body fatness, energy metabolism, caloric intake, and sexual dimorphism. Diabetes. 46:989-993.

34. Agrawal R, Sladkevicius P, Engmann L, et al. 1998 Serum vascular endothelial growth factor concentrations and ovarian stromal blood flow are increased in women with polycystic ovaries. Hum Reprod. 13:651-655.

35. Fauser BC, Pache TD, Lamberts SW, Hop WC, de Jong FH, Dahl KD. 1991 Serum bioactive and immunoreactive luteinizing hormone and follicle-stimulating hormone levels in women with cycle abnormalities, with or without polycystic ovarian disease. J Clin Endocrinol Metab. 73:811-817.

36. Poretsky L. 1991 On the paradox of insulin-induced hyperandrogenism in insulin-resistant states. Endocr Rev. 12:3-13.

37. Poretsky L, Chandrasekher YA, Bai C, Liu HC, Rosenwaks Z, Giudice LC. 1996 Insulin receptor mediates inhibitory effect of insulin, but not of insulinlike growth factor (IGF)-I, on IGF binding protein 1 (IGFBP-1) production in human granulosa cells. J Clin Endocrinol Metab. 81:493-496.

38. Legro RS, Spielman R, Urbanek M, Driscoll D, Strauss JF, Dunaif A. 1998 Phenotype and genotype in polycystic ovary syndrome. Recent Prog Horm Res. 53:217-56:217-256.

39. Weaver JU, Holly JM, Kopelman PG, et al. 1990 Decreased sex hormone binding globulin (SHBG) and insulin-like growth factor binding protein (IGFBP-1) in extreme obesity. Clin Endocrinol (Oxf). 33:415-422.

40. Nestler JE, Powers LP, Matt DW, et al. 1991 A direct effect of hyperinsulinemia on serum sex hormone-binding globulin levels in obese women with the polycystic ovary syndrome. J Clin Endocrinol Metab. 72:83-89.

41. Yki-Jarvinen H, Makimattila S, Utriainen T, Rutanen EM. 1995 Portal insulin concentrations rather than insulin sensitivity regulate serum sex hormonebinding globulin and insulin-like growth factor binding protein 1 in vivo. J Clin Endocrinol Metab. 80:3227-3232.

42. Butzow TL, Kettel LM, Yen SS. 1995 Clomiphene citrate reduces serum insulin-like growth factor I and increases sex hormone-binding globulin levels in women with polycystic ovary syndrome. Fertil Steril. 63:1200-1203.

43. Nestler JE, Jakubowicz DJ. 1997 Lean women with polycystic ovary syndrome respond to insulin reduction with decreases in ovarian $\mathrm{P} 450 \mathrm{c} 17 \alpha$ activity and serum androgens. J Clin Endocrinol Metab. 82:4075-4079.

44. Dunaif A, Scott D, Finegood D, Quintana B, Whitcomb R. 1996 The insulinsensitizing agent troglitazone improves metabolic and reproductive abnormalities in the polycystic ovary syndrome. J Clin Endocrinol Metab. 81:3299-3306.

45. Cataldo NA, Giudice LC. 1992 Insulin-like growth factor binding protein profiles in human ovarian follicular fluid correlate with follicular functional status. J Clin Endocrinol Metab. 74:821-829.

46. San Roman GA, Magoffin DA. 1992 Insulin-like growth factor binding proteins in ovarian follicles from women with polycystic ovarian disease: cellular source and levels in follicular fluid. J Clin Endocrinol Metab. 75:1010-1016.

47. LeRoith D, Werner H, Beitner-Johnson D, Roberts CTJ. 1995 Molecular and cellular aspects of the insulin-like growth factor I receptor. Endocr Rev. $16: 143-163$.

48. Tiitinen AE, Laatikainen TJ, Seppala MT. 1993 Serum levels of insulin-like growth factor binding protein-1 and ovulatory responses to clomiphene citrate in women with polycystic ovarian disease. Fertil Steril. 60:58-62.

49. Nelson VL, Legro RS, Strauss JF, McAllister JM. 1999 Augmented androgen production is a stable steroidogenic phenotype of propagated theca cells from polycystic ovaries. Mol Endocrinol. 13:946-957.

50. Zachow RJ, Magoffin DA. 1997 Direct intraovarian effects of leptin: impair ment of the synergistic action of insulin-like growth factor-I on follicle-stimulating hormone-dependent estradiol- $17 \beta$ production by rat ovarian granulosa cells. Endocrinology. 138:847-850.

51. Agarwal SK, Vogel K, Weitsman SR, Magoffin DA. 1999 Leptin antagonizes the insulin-like growth factor-I augmentation of steroidogenesis in granulosa and theca cells of the human ovary. J Clin Endocrinol Metab. 84:1072-1076.

52. Messinis IE, Milingos SD, Alexandris E, Kariotis I, Kollios G, Seferiadis K. 1999 Leptin concentrations in normal women following bilateral ovariectomy. Hum Reprod. 14:913-918.

53. Carantoni M, Abbasi F, Azhar S, Schaaf P, Reaven GM. 1999 Can changes in plasma insulin concentration explain the variability in leptin response to weight loss in obese women with normal glucose tolerance? J Clin Endocrinol Metab. 84:869-872.

54. Kiddy DS, Hamilton-Fairley D, Seppala M, et al. 1989 Diet-induced changes in sex hormone binding globulin and free testosterone in women with normal or polycystic ovaries: correlation with serum insulin and insulin-like growth factor-I. Clin Endocrinol (Oxf). 31:757-763.

55. Hollmann M, Runnebaum B, Gerhard I. 1996 Effects of weight loss on the hormonal profile in obese, infertile women. Hum Reprod. 11:1884-1891. 